\title{
IMPLEMENTASI DATABASE APLIKASI INVENTORY
}

\author{
Muhammad Aldi S \\ 155100048, 785567950 \\ Fakultas Komputer \\ muhammadaldisujana.student@umitra.ac.id
}

\begin{abstract}
Inventory merupakan kata lain dari persediaan, istilah persediaan disini maksudnya menujukkan barang-barang yang dimiliki perusahaan. Persediaan dapat mengambil bentuk yang tergantung pada jenis usaha yang ditekuni oleh perusahaan yang bersangkutan. TB.Cipta Karya merupakan sebuah badan usaha yang bergerak dibidang penjualan bahan bangunan. Pada TB.Cipta Karya, data barang disimpan dalam bentuk tumpukan faktur pembelian yang memungkinkan terjadinya kehilangan data barang, perhitungan setiap transaksi masih menggunakan perhitungan manual sehingga memungkinkan terjadinya kesalahan terhadap jumlah total harga, pengendalian terhadap persediaan barang masih kurang terkontrol serta pembuatan laporan yang dilakukan pada TB.Cipta Karya yaitu dengan mencatat seluruh transaksi yang telah dilakukan. Untuk mengatasi permasalahan yang terdapat pada TB.Cipta Karya, maka diperlukan pemanfaatan teknologi seperti komputer beserta program aplikasi yang dapat membantu proses pengolahan data pembelian, penjualan, persediaan barang, serta pembuatan laporan secara cepat dan akurat. Sistem baru yang dirancang menggunakan Adobe Dreamweaver sebagai software untuk membuat sistem informasi inventory, dan MySQL sebagai perancangan database. Penelitian ini menghasilkan suatu aplikasi program yang dapat mempermudah dalam penyimpanan data serta pencarian data barang yang dibutuhkan, mempermudah perhitungan setiap transaksi, pengendalian terhadap persediaan barang bisa terkontrol baik, serta mempermudah pembuatan laporan.
\end{abstract}

Kata Kunci : Inventory, Adobe Dreamweaver, MySQL, Database 


\section{A. INTRODUCTION}

Saat ini perkembangan teknologi khususnya teknologi komputer berkembang sangat cepat. Teknologi komputer mempermudah manusia untuk melakukan semua pekerjaannya. Perkembangan hardware dan software yang semakin murah dan komplek memungkinkan manusia saat ini memanfaatkan teknologi komputer dalam semua aspek kehidupannya mulai dari perkantoran, pendidikan, hiburan, industri, dan masih banyak lagi. Dengan teknologi komputer memungkinkan mempermudah manusia dalam menyelesaikan pekerjaannya, menghemat biaya, waktu serta pelaporannya sehingga mempercepat pengambilan keputusan. Inventory merupakan kata lain dari persediaan, istilah persediaan disini maksudnya menujukkan barangbarang yang dimiliki perusahaan. Persediaan dapat mengambil bentuk yang tergantung pada jenis usaha yang ditekuni oleh perusahaan yang bersangkutan. Pada perusahaan yang bergerak dibidang penjualan produk, persediaan barang merupakan salah satu unsur yang paling efektif dalam operasional perusahaan, yang secara berkelanjutan digunakan dalam kegiatan penjualan barang harian yang dapat disajikan dalam bentuk laporan persediaan barang. TB.Cipta Karya merupakan sebuah badan usaha yang bergerak dibidang penjualan bahan bangunan. Pada TB. Cipta Karya, data barang disimpan dalam bentuk tumpukan faktur pembelian yang memungkinkan terjadinya kehilangan data barang. Perhitungan setiap transaksi masih menggunakan perhitungan manual sehingga memungkinkan terjadinya kesalahan terhadap jumlah total harga. Pengendalian terhadap persediaan barang masih kurang terkontrol karena barang yang dibeli dan yang dijual tidak terinci sehingga tidak diketahui dengan pasti barang apa saja yang ada 
dan berapa jumlah stok barang yang tersedia pada TB. Cipta Karya. Pembuatan laporan yang dilakukan pada TB.Cipta Karya yaitu dengan mencatat seluruh transaksi yang telah dilakukan sehingga akan memakan waktu yang lama. Oleh karena itu, untuk mengatasi permasalahan yang terdapat pada TB.Cipta Karya, maka diperlukan pemanfaatan teknologi seperti komputer beserta program aplikasi yang dapat membantu proses pengolahan data pembelian, penjualan, persediaan barang, serta pembuatan laporan secara

cepat dan akurat.

\section{B. CONTENT}

Implementasi ini dilakukan agar pemakai sistem dapat mengerti tentang bagaimana cara bekerja dari sistem ini. Berikut adalah Implementasi dari Sistem Informasi Inventori pada TB. Cipta Karya.

\section{a.Form Menu Utama}

Menu utama tampilan awal yang merupakan form dari satu rancangan program untuk memudahkan admin dalam menjalankan program, sehingga pada saat menjalankan komputer admin

tidak mengalami kesulitan dalam memilih menu-menu yang ingin digunakannya.

\section{b.Form Data Barang}

Berikut ini adalah form data barang, cara menampilkan form data barang langkah pertama yaitu admin mengklik tombol master yang ada dimenu utama kemudian admin mengklik master data barang, admin dapat menginput data barang sesuai dengan tampilan yang ada dengan mengisi data secara lengkap, kemudian admin dapat menekan tombol simpan untuk menyimpan maka data barang akan tersimpan, ataupun admin dapat mengklik tombol batal jika ingin membatalkan penginputan, admin juga dapat melakukan pencarian data barang berdasarkan jenis barang, merk, harga, ataupun discount. Jika data barang telah tampil maka akan muncul tiga aksi yaitu lihat data barang untuk melihat detail data barang tersebut, ubah data barang apabila ada perubahan pada data barang, dan hapus data barang jika ingin menghapus data barang tersebut. 


\section{CONCLUSION}

Perancangan dan Implementasi Sistem

Informasi Inventory pada TB. Cipta Karya merupakan perancangan dari sistem yang sedang berjalan. Berbagai permasalahan yang muncul telah diupayakan untuk dapat ditangani dengan sistem yang baru ini, adapun kesimpulan yang dapat diambil antara lain sebagai berikut :

1. Setelah diterapkannya Sistem Informasi Inventory pada TB. Cipta Karya, akan mempermudah pihak TB. Cipta Karya dalam hal penyimpanan data serta pencarian data barang yang dibutuhkan.

2. Setelah diterapkannya Sistem Informasi Inventory ini, maka akan mempermudah pihak TB.Cipta Karya dalam hal perhitungan setiap transaksi pembelian dan penjualan.

3. Setelah diterapkannya Sistem Informasi Inventory ini pengendalian terhadap persediaan barang bisa terkontrol baik, sehingga dapat diketahui dengan pasti berapa jumlah barang yang tersedia pada TB. Cipta Karya.

4. Setelah diterapkannya Sistem Informasi Inventory pada TB. Cipta
Karya, akan mempermudah pembuatan laporan, seperti pembuatan laporan pembelian, laporan penjualan, serta laporan stok barang.

\section{DISCUSSION}

1. Dalam tahap pengembangan selanjutnya, disarankan agar dapat menambahkan fasilitas-fasilitas ataupun alat yang sekiranya menunjang untuk kelancaran dalam proses informasi, seperti penambahan fasilitas program yang memadai.

2. Perlu adanya pengembangan dan pemeliharaan yang lebih baik lagi terhadap sistem yang telah dibuat, sehingga sistem dapat dipergunakan sesuai dengan kebutuhan.

3. Mempertahankan kinerja yang baik yang telah dicapai dan dilaksanakan oleh pihak TB. Cipta Karya. 


\section{E. REFERENCE}

[1] O. M. Febriani and A. S. Putra, "Sistem Informasi Monitoring Inventori Barang Pada Balai Riset Standardisasi Industri Bandar Lampung," J. Inform., vol. 13, no. 1, pp. 90-98, 2014.

[2] A. S. Putra, "Paperplain: Execution Fundamental Create Application With Borland Delphi 7.0 University Of Mitra Indonesia," 2018.

[3] A. S. Putra, "2018 Artikel Struktur Data, Audit Dan Jaringan Komputer," 2018.

[4] A. S. Putra, "ALIAS MANAGER USED IN DATABASE DESKTOP STUDI CASE DB DEMOS."

A. S. Putra, "COMPREHENSIVE SET OF PROFESSIONAL FOR DISTRIBUTE COMPUTING."

[6] A. S. Putra, "DATA ORIENTED RECOGNITION IN BORLAND DELPHI 7.0."

[7] A. S. Putra, "EMBARCADERO DELPHI XE 2 IN GPUPOWERED FIREMONKEY APPLICATION."

[8] A. S. Putra, "HAK ATAS KEKAYAAN INTELEKTUAL DALAM DUNIA TEKNOLOGY BERBASIS REVOLUSI INDUSTRI 4.0."

[9] A. S. Putra, "IMPLEMENTASI PERATURAN PERUNDANGAN UU. NO 31 TAHUN 2000 TENTANG DESAIN INDUSTRI BERBASIS INFORMATION 
TECHNOLOGY."

A.

$\mathrm{S}$.

Putra,

"IMPLEMENTATION OF PARADOX DBASE."

A.

S.

Putra, "IMPLEMENTATION OF TRADE SECRET CASE STUDY SAMSUNG MOBILE PHONE."

A. S. Putra, "IMPLEMENTATION PATENT FOR APPLICATION WEB BASED CASE STUDI WWW. PUBLIKLAMPUNG. COM."

[13] A.

"IMPLEMENTATION

SYSTEM FIRST TO INVENT

IN DIGITALLY INDUSTRY."

[14] A. S. Putra, "MANUAL REPORT \& INTEGRATED DEVELOPMENT

ENVIRONMENT BORLAND DELPHI 7.0."

[15] A. S. Putra, "PATENT AS RELEVAN "SUPPORT RESEARCH."

[16] A. S. Putra, "PATENT FOR RESEARCH STUDY CASE OF APPLE. Inc."

[17] A. S. Putra, "PATENT PROTECTION FOR APPLICATION INVENT."

[18] A. S. Putra, "QUICK REPORT IN PROPERTY PROGRAMMING."

[19] A. S. Putra, "REVIEW CIRCUIT LAYOUT COMPONENT

REQUIREMENT ON ASUS NOTEBOOK."

[20] A. S. Putra, "REVIEW TRADEMARK PATENT FOR INDUSTRIAL

TECHNOLOGY BASED 4.0."
[21] A. S. Putra, "TOOLBAR COMPONENT PALLETTE IN OBJECT ORIENTED PROGRAMMING."

[22] A. S. Putra, "WORKING DIRECTORY SET FOR PARADOX 7."

[23] A. S. Putra, "ZQUERY CONNECTION

IMPLEMENTED

PROGRAMMING STUDI CASE PT. BANK BCA Tbk."

[24] A. S. Putra, D. R. Aryanti, and I. Hartati, "Metode SAW (Simple Additive Weighting) sebagai Sistem Pendukung Keputusan Guru Berprestasi (Studi Kasus: SMK Global Surya)," in Prosiding Seminar Nasional Darmajaya, 2018, vol. 1, no. 1, pp. 85-97.

[25] A. S. Putra and O. M. Febriani, "Knowledge Management Online Application in PDAM Lampung Province," in Prosiding International conference on Information Technology and Business (ICITB), 2018, pp. 181-187.

[26] A. S. Putra, O. M. Febriani, and B. Bachry, "Implementasi Genetic Fuzzy System Untuk Mengidentifikasi Hasil Curian Kendaraan Bermotor Di Polda Lampung," SIMADA (Jurnal Sist. Inf. dan Manaj. Basis Data), vol. 1, no. 1, pp. 21-30, 2018.

[27] A. S. Putra, H. Sukri, and K. Zuhri, "Sistem Monitoring Realtime Jaringan Irigasi Desa (JIDES) Dengan Konsep Jaringan Sensor Nirkabel," IJEIS (Indonesian J. Electron. Instrum. Syst., vol. 8, no. 2, pp. 
221-232.

[28] D. P. Sari, O. M. Febriani, and A. S. Putra, "Perancangan Sistem Informasi SDM Berprestasi pada SD Global Surya," in Prosiding Seminar Nasional Darmajaya, 2018, vol. 1, no. 1, pp. 289-294. 